\title{
Chemically Reduced Graphene Oxide on Gold Electrodes from Recordable CDs: Characterization and Potential Sensing Applications
}

\author{
Francisco D. da Silva, ${ }^{a}$ Diego P. Rocha, ${ }^{b}$ Murilo N. T. Silva, ${ }^{b}$ Edson Nossol, ${ }^{b}$ \\ Rodrigo A. A. Muñoz, ${ }^{\circledR *}{ }^{*}$ Felipe S. Semaan ${ }^{a}$ and Rafael M. Dornellas $*, a$ \\ ${ }^{a}$ Departamento de Química Analítica, Instituto de Química, Universidade Federal Fluminense, \\ 24020-141 Niterói-RJ, Brazil \\ ${ }^{b}$ Instituto de Química, Universidade Federal de Uberlândia, 38400-902 Uberlândia-MG, Brazil
}

\begin{abstract}
This work presents the development and characterization of a new chemically modified electrode exploiting recordable Au-rewritable compact discs (AuCDs) as substrate for drop casting of a chemically-reduced graphene-oxide slurry focusing on simple and low-cost electrochemical sensors. Increase in electrochemical responses in cyclic voltammetric and amperometric measurements were achieved using the proposed sensor. Both scanning electron microscopy and atomic force microscopy data showed increase in rugosity (about $46 \%$ higher) for the chemically reduced graphene oxide (CRGO) AuCD surface while Raman spectroscopy confirmed the presence of structural defects of graphene. The calculated charge transfer resistances $\left(\mathrm{R}_{\mathrm{ct}}\right)$ and heterogeneous electron transfer rate constants $\left(\mathrm{k}_{0}\right)$ were $1638 \Omega$ and $0.0022 \mathrm{~cm} \mathrm{~s}^{-1}$ for the bare substrate, and $91 \Omega$ and $0.0027 \mathrm{~cm} \mathrm{~s}^{-1}$ for the modified electrode, evidencing the facilitated electron transfer of the CRGO-AuCD surface. The dopamine (DP) amperometric detection using CRGO-AuCD provided low detection limit $\left(0.12 \mu \mathrm{g} \mathrm{L}^{-1}\right)$ compared with other modified electrodes already reported, high precision (relative standard deviation $(\mathrm{RSD})<5 \%$ ) and analytical frequency $\left(370 \mathrm{~h}^{-1}\right)$. As a proof-of-concept, DP determination in synthetic saliva samples was performed and a satisfactory recovery value $(98.6 \pm 0.9 \%)$ was obtained.
\end{abstract}

Keywords: disposable electrodes, dopamine, saliva, modified electrodes, graphene, gold electrode

\section{Introduction}

Since the establishment of polarography as an analytical technique by Heyrosvsky, ${ }^{1,2}$ the electrochemical behavior of chemical species onto metallic electrodic surfaces has raised interest in many fields of science. ${ }^{3}$ From the use of ultrapure liquid mercury to nanostructured devices, passing through bulk noble metals, a wide range of electrodes has been investigated in electroanalysis, considering both analyte and media properties, samples and technique to be applied. ${ }^{4}$ In this context, chemically modified electrodes were developed and play key role in the development of electrochemical sensors. ${ }^{5-7}$

Carbon-based electrochemical sensors have been widely used in electroanalysis due to the particular properties of carbon materials, including chemical stability, strong mechanical resistance and excellent thermal and electrical

*e-mail: munoz@ufu.br; rafaeldornellas@id.uff.br conductivities, in addition to low costs of preparation and long-term stability. ${ }^{8-10}$ Among all possible allotropes of carbon, from graphite to fullerenes and nanotubes, 2D particles, such as graphene, have received special attention. Graphene is composed of a single sheet of carbon atoms conjugated with $\mathrm{sp}^{2}$ hybridization, with an open double-sided surface that can undergo a wide class of organic reactions analogous to unsaturated systems in organic molecules. ${ }^{11}$ The oxidized form of graphene (graphene oxide) is prepared by several routes, mainly by the method of Hummers. ${ }^{12,13}$ Reduction of graphene oxide (RGO) can be achieved in a number of ways, such as thermal, photocatalytic, chemical and electrochemical processes, producing defective (modified) surfaces with oxygenated functional groups at their edges. ${ }^{14}$ This reduction makes graphene oxide of great application for electrochemical sensors due to the reestablishment of carbon atoms conjugated with $\mathrm{sp}^{2}$ hybridization that leads to increase in conductivity. ${ }^{15}$ In general, the use of RGO as chemical modifier onto 
different surfaces increases the electron transfer kinetics resulting in an electrocatalytic effect, allowing, thus, a better understanding of many electrochemical pathways and thus improving electroanalytical performance in many aspects. ${ }^{16-20}$ When comparing to graphite, the smaller size of graphene and its crystalline defects provide relevant advantages when modifying electrochemical substrates wither by drop-casting to control the relationship conductivity/particle size $\mathrm{e}^{14}$ or by film deposition as graphite particles do offer stable homogenous films. ${ }^{21}$

Different substrates have been used to incorporate chemical modifiers, such as solid noble metal disc electrodes and especially glassy-carbon disc electrode. These substrates require surface renewal by mechanical polishing in alumina suspension to generate a clean surface before modification. This process has as main disadvantage its irreproducibility as the polishing is typically hand-made; moreover, residual alumina on the surface can interfere on the electrochemical profile of different species. ${ }^{22,23} \mathrm{An}$ elegant strategy to obtain gold substrates in a reproducible and low-cost manner is the chemical removal of the polymeric protective layer of commercially available Aurewritable compact discs (AuCD). ${ }^{24}$ Reaction with nitric acid within minutes or physical removal using adhesive scotch tape were described to enable the thin gold layer accessible as an electrochemical substrate. ${ }^{25}$ Chemical modification with multiple-walled carbon nanotubes, ${ }^{26}$ silver nanoparticles (AgNPs) ${ }^{27}$ and platinum film ${ }^{28}$ has been reported for the development of improved electrochemical sensors using such an inexpensive source of electrodes compared to conventional disc gold electrodes.

In this context, the main goal of this work was to exploit the possibility of using AuCD as substrate for the construction of a disposable chemically modified electrode (CME). In this sense, the modification was based on the drop casting of chemically reduced graphene oxide onto the AuCD (CRGO-AuCD). As a proof-ofconcept, the proposed sensor was applied to determine the neurotransmitter dopamine (DP) using batch-injection analysis (BIA) with amperometric detection. BIA is easily combined with amperometric detectors offering precise and fast analysis by injecting microvolume plugs under precise control of volume and rate. ${ }^{29}$ Dopamine was selected because it presents a well-known chemical and electrochemical behavior and the analytical performance of the sensor can be compared with the literature. ${ }^{30}$ At first, it becomes relevant to consider that not only dopamine, but also cortisol and salivary amylase are present in saliva, being relevant biomarkers while assessed in combination one to each other. Stress conditions can lead to increased short-term levels of salivary amylase while such increment only can be noted in cortisol in long-term evaluations, being dopamine levels kept almost constant, which allows analysts to use a normalized scale between dopamine and the others. In fact, such correction could be recommended since many other conditions such as use of medication, age and gender can alter levels for all cited markers, being thus a suitable alternative to the development of lab-on-a-chip tools for clinical analysis. ${ }^{31-33}$

\section{Experimental}

Reagents, solutions and sample

All chemicals used were of analytical grade of purity and used as received, all aqueous solutions were prepared by direct solubilization in ultra-pure deionized water (resistivity $\geq 18.2 \mathrm{M} \Omega \mathrm{cm}$ ) obtained by Millipore Direct-Q3 water purification system (Bedford, MA, USA). Perchloric acid (72\%, v/v), nitric acid $(65 \%, \mathrm{~m} / \mathrm{m})$, potassium ferrocyanide $(99 \%, \mathrm{~m} / \mathrm{m})$, potassium thiocyanate $(99 \%, \mathrm{~m} / \mathrm{m})$, potassium chloride $(99 \%, \mathrm{~m} / \mathrm{m})$, sodium bicarbonate $(99.7 \%, \mathrm{~m} / \mathrm{m})$, sodium monobasic phosphate $(98 \%, \mathrm{~m} / \mathrm{m})$, lactic acid $(85 \%, \mathrm{~m} / \mathrm{m})$, and sulfuric acid $\left(98 \%, \mathrm{~m} / \mathrm{m}\right.$ ) were purchased from Vetec ${ }^{\circledR}$ (Rio de Janeiro, Brazil), and dopamine $(99 \%, \mathrm{~m} / \mathrm{m})$ from Sigma Aldrich ${ }^{\circledR}$ (São Paulo, Brazil). Dimethylformamide (DMF) (99.94\%, $\mathrm{m} / \mathrm{m}$ ) was obtained from Sigma Aldrich ${ }^{\circledR}$ (Steinheim, Germany) and J. T. Baker ${ }^{\circledR}$ (Ciudad de México, México), respectively. A solution containing $0.1 \mathrm{~mol} \mathrm{~L}^{-1}$ of perchloric acid was used as background electrolyte. All stock and work solutions were prepared in the supporting electrolyte prior to the experiment's execution.

Chemically reduced graphene oxide (CRGO) was obtained by reduction from graphene oxide (GO) with $\mathrm{NaBH}_{4}$, in the proportion of $1.0 \mathrm{~mL}$ of aqueous dispersion of $\mathrm{GO}$ to $6.0 \mathrm{mg} \mathrm{NaBH}_{4}$, according to an adaptation from the literature. ${ }^{14}$ In the present approach, the starting GO was obtained from natural graphite by the method of Hummers.

Synthetic saliva sample was prepared according to a previous work, ${ }^{34}$ consisting of an aqueous mixture of $5.3 \mathrm{mmol} \mathrm{L}^{-1} \mathrm{KSCN}, 15 \mathrm{mmol} \mathrm{L}{ }^{-1} \mathrm{NaHCO}_{3}, 20 \mathrm{mmol} \mathrm{L}^{-1}$ $\mathrm{KCl}, 1.4 \mathrm{mmol} \mathrm{L}-1 \mathrm{NaH}_{2} \mathrm{PO}_{4}$ and $10 \mathrm{mmol} \mathrm{L}^{-1}$ lactic acid.

\section{Apparatus}

Voltammetric and amperometric measurements were carried out using a potentiostat/galvanostat Ivium ${ }^{\circledR}$ Compact Stat B09118 (Ivium Technologies, The Netherlands), controlled by IviumSoft ${ }^{\circledR}$ software. Electrochemical impedance spectroscopy (EIS) was performed using the FRA2 module coupled to the PGSTAT $128 \mathrm{~N}$ potentiostat 
(Eco Chemie ${ }^{\circledR}$-Methrom, The Netherlands). The proposed working electrodes (bare or chemically modified gold electrode from the recordable CDs obtained from Mitsui ${ }^{\circledR}$, São Paulo, Brazil) were assessed in a three-electrode electrochemical set up with a miniaturized $\mathrm{Ag}|\mathrm{AgCl}| \mathrm{KCl}_{\text {sat. }}{ }^{35}$

Scanning electron microscopy (SEM) measurements were obtained by operating a Vega 3 LMU (Tescan ${ }^{\circledR}$, Brno-Kohoutovice, Czech Republic) at $10 \mathrm{kV}$.

Raman spectrum (Raman) of the modified electrode was acquired utilizing a LabRAM HR Evolution microscope (Horiba ${ }^{\circledR}$, Kyoto, Japan), using an argon ion laser $(\lambda=532 \mathrm{~nm})$, with an incidence power of $1 \%$ in the range $4000-200 \mathrm{~cm}^{-1}$.

Atomic force microscopy (AFM) measurements were obtained from a Nanosurf FlexAFM C3000 Controller (NanoSurfs ${ }^{\circledR}$, Liestal, Switzerland).

\section{AuCD preparation and its modification with CRGO}

A recordable gold CD (Mitsui, Tokyo, Japan) disc was used to manufacture the working electrode following a procedure adapted from the literature. ${ }^{23}$ For the removal of the polymer layer from the $\mathrm{CD}$ surface, approximately $100 \mu \mathrm{L}$ of nitric acid $(65 \%, \mathrm{~m} / \mathrm{m})$ was added over the $\mathrm{CD}$ and left for about $10 \mathrm{~min}$ until the surface became roughness which indicated the release of the polymeric film from the gold surface. The polymer layer was mechanically removed with ultra-pure water and the obtained CD (with the gold surface exposed) was cut into specific sizes to be adapted to the electrochemical cell.

The modification of the AuCD surface with CRGO was adapted from the literature, ${ }^{14}$ in which $1.0 \mathrm{mg}$ of reduced graphene oxide was placed in DMF, being the system submitted to sonication during $10 \mathrm{~min}$ with the aid of a tip ultrasound (Vibra Cell ${ }^{\circledR}$, Sonics and Materials, Newton, USA) adjusted to pulses of $5 \mathrm{~s}$ on and $2 \mathrm{~s}$ off, with $40 \%$ amplitude. The suspension obtained was, then, used for the chemical modification of the gold substrate by drop casting method: $10 \mu \mathrm{L}$ of the suspension was added, using a micropipette, to the electrode surface and left on heating $\left(60{ }^{\circ} \mathrm{C}\right)$ for $30 \mathrm{~min}$ for complete solvent evaporation.

\section{Electrochemical measurements}

Static measurements (such as cyclic voltammetry (CV) and EIS) and hydrodynamic measurements (such as amperometric screening and determination) were performed using two different labmade electrochemical cells. The first one (static measurements) presents an internal volume of $10.0 \mathrm{~mL}$; the second one, for BIA measurements, the total volume is $80 \mathrm{~mL}$. Both cells were constructed using a 3D-printer equipped with a fused-deposition modeling (FDM) filled by acrylonitrile butadiene styrene (ABS) filament following a procedure developed by our research group. ${ }^{36}$ The working electrode area was determined by a hole at the bottom of both cells of $1.00 \mathrm{~cm}$ of inner diameter. In the BIA cell, the micropipette (Multipette ${ }^{\circledast}$ stream, Eppendorf, Hamburg, Germany) was placed $2 \mathrm{~mm}$ from the working electrode in a wall-jet configuration. ${ }^{37} \mathrm{An}$ electronic pipette was used to control the injection volumes between 10 and $1000 \mu \mathrm{L}$ under the injection rates between 28 and $345 \mu \mathrm{L} \mathrm{s}^{-1}$. EIS measurements were carried out in the presence of $1 \mathrm{mmol} \mathrm{L}^{-1}$ of ferricyanide/ferrocyanide (in $0.1 \mathrm{~mol} \mathrm{~L}^{-1} \mathrm{KCl}$ as supporting electrolyte) from 50000 to $0.1 \mathrm{~Hz}$ frequency range, adjusted with amplitude of $10 \mathrm{mV}$ (10 data points per decade of frequency). The charge transfer resistance $\left(R_{c t}\right)$ values were acquired via non-linear regression of the semicircle portion of the Nyquist plot through the $\mathrm{NOVA}^{\circledR} 1.11$ software analysis.

\section{Results and Discussion}

\section{Characterization}

In order to evaluate changes on the morphology occurred at the electrode surface after the modification with CRGO, SEM measurements were performed. Figure 1 shows the surface morphology of AuCD (Figure 1a) and CRGO-AuCD (Figures 1b-1d). The bare gold surface (Figure 1a) presents a smooth area with the parallel channels corresponding to the grooves where the data is recorded. ${ }^{24}$ The CRGO-AuCD images are completely different, as they display the modified surface composed of a heterogeneous structure composed by graphene sheets with different sizes, with a good material dispersion along the electrode surface. SEM images also revealed that the film is constituted by multi-layer RGO sheets.

AFM images of the electrodes are shown in Figures 1e-1f. Through the AFM data, the rugosity values were estimated as 27.8 and $40.8 \mathrm{~nm}$ for AuCD and CRGO-AuCD, respectively. These results are in accordance with the results obtained via SEM. Thus, the modified surface provided higher surface area (about $46 \%$ higher) which can affect directly the electrochemical performance.

Figure 2 presents the Raman spectrum for the CRGO-AuCD electrode. It is possible to observe the presence of three bands associated with graphitic materials as reported in the literature. ${ }^{34}$ The first band at $1338 \mathrm{~cm}^{-1}$ (named D-band) is related to the vibration mode of the carbon atoms in the aromatic ring, this band is prohibited, thus indicating the presence of structural defects in the graphene sheets, such as presence of functional oxygenated groups and incomplete 

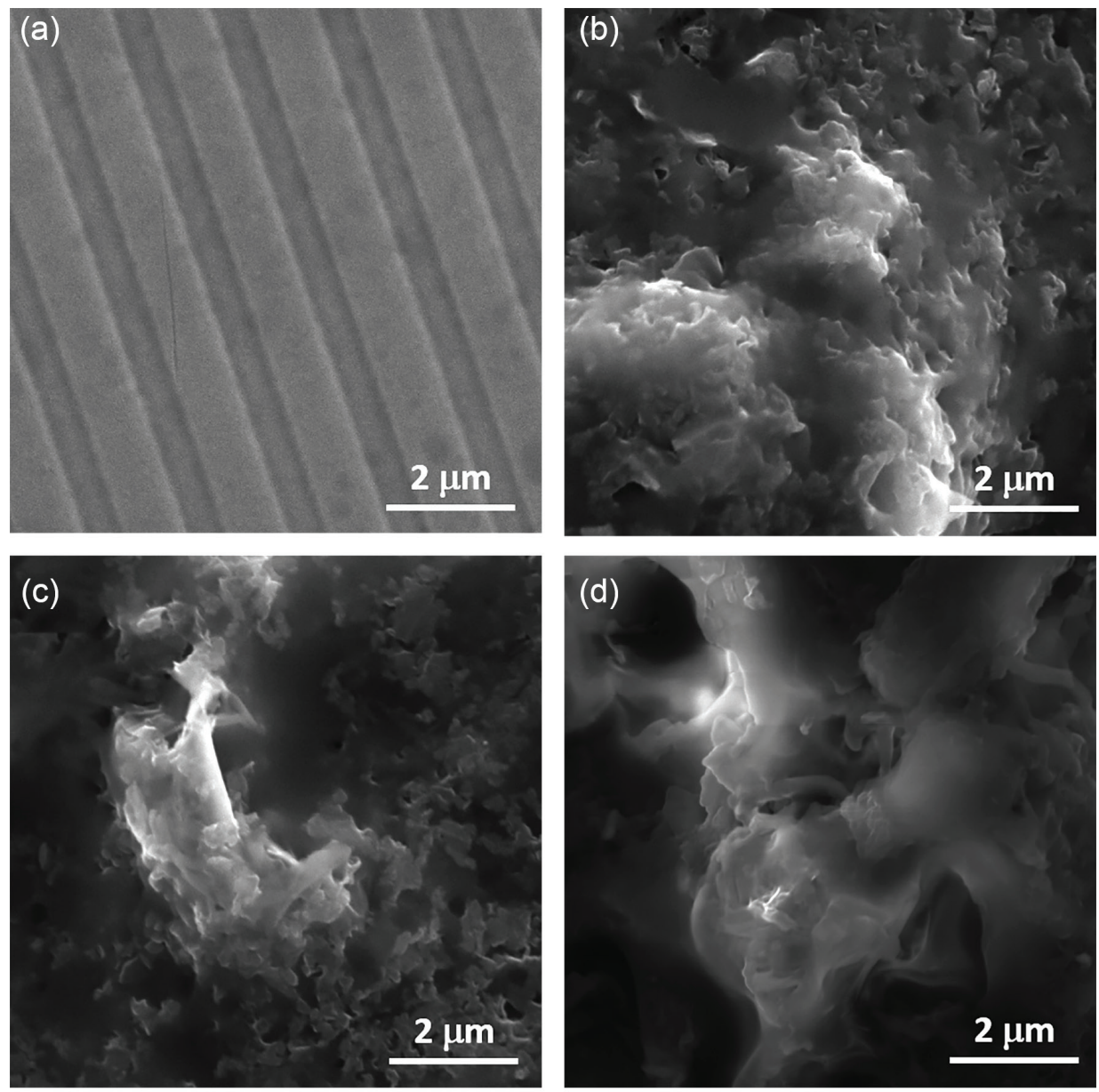

(e)

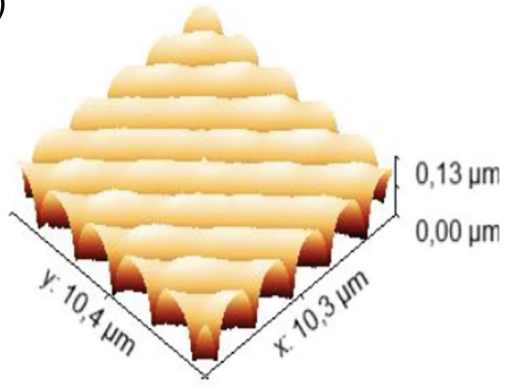

(f)

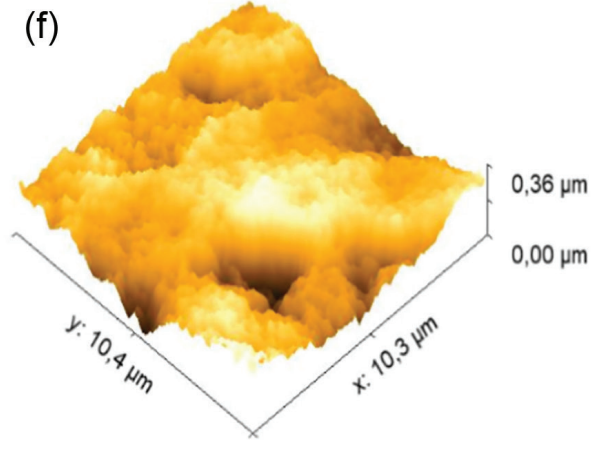

Figure 1. SEM images for AuCD (a) and CRGO-AuCD (b-d) and AFM images for AuCD (e) and CRGO-AuCD (f).

$\mathrm{sp}^{3}$ bonds. The second band at $1596 \mathrm{~cm}^{-1}$ (called G-band) is associated with the stretching of the $\mathrm{C}=\mathrm{C}$ bond present in the CRGO structure. The third band located at approximately $2700 \mathrm{~cm}^{-1}$ (called 2D-band, or G'-band) is generated by a second order Raman scatter and is associated with a D-band overtone, being associated with the organization in the two-dimensional plane of the CRGO structure.

\section{Electrochemical measurements}

Aiming to evaluate a possible improvement in electronic transfer after the electrode modification with
CRGO, EIS measurements were applied, being the results displayed in Figure 3. It can be seen that the bare electrode provided higher resistance to charge transfer $\left(\mathrm{R}_{\mathrm{ct}}\right)$ (18-fold higher), evidenced via the higher portion of the Nyquist semicircle (Figure 3a), when compared to modified electrode. This result indicates that the electron transfer of the redox probe is facilitated while using the modified AuCD with CRGO. Figure $3 \mathrm{~b}$ shows the cyclic voltammogram recordings and the results obtained are in accordance with the EIS data, since the modified surface provided lower impedance and consequently presented the higher current value. Therefore, based on what has been 


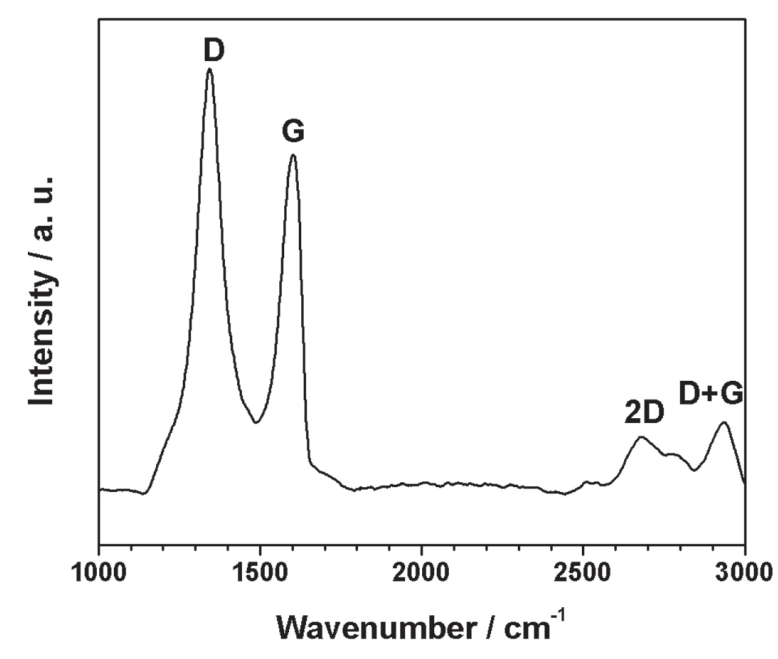

Figure 2. Raman spectrum of CRGO-AuCD.

discussed so far, the CRGO-AuCD is a great promise as a new electrochemical sensor.

Using the Randles-Sevick equation, the electroactive areas of bare and modified surfaces were estimated. For this, cyclic voltammograms were performed utilizing as redox probe $1 / 1 \mathrm{mmol} \mathrm{L}^{-1} \mathrm{~K}_{3} \mathrm{Fe}(\mathrm{CN})_{6} / \mathrm{K}_{4} \mathrm{Fe}(\mathrm{CN})_{6}$ in $0.1 \mathrm{~mol} \mathrm{~L}^{-1}$ $\mathrm{KCl}$ solution. The calculated electroactive areas were $1.8 \times 10^{-2}$ and $3.6 \times 10^{-2} \mathrm{~cm}^{2}$ for the unmodified and modified surfaces, respectively. The modified surface presented an electroactive area twice higher than the unmodified surface, which exceeds the improvement on signals expected merely by improvement on roughness (measured by SEM and AFM analyses). The heterogeneous electron transfer (HET) rate constant $\left(\mathrm{k}_{0}\right)$ of the bare and modified electrodes were calculated via the Nicholson method. ${ }^{38}$ The calculated $\mathrm{k}_{0}$ values were $2.2 \times 10^{-3}$ and $2.7 \times 10^{-3} \mathrm{~cm} \mathrm{~s}^{-1}$ for bare and modified electrode, respectively. The modified surface

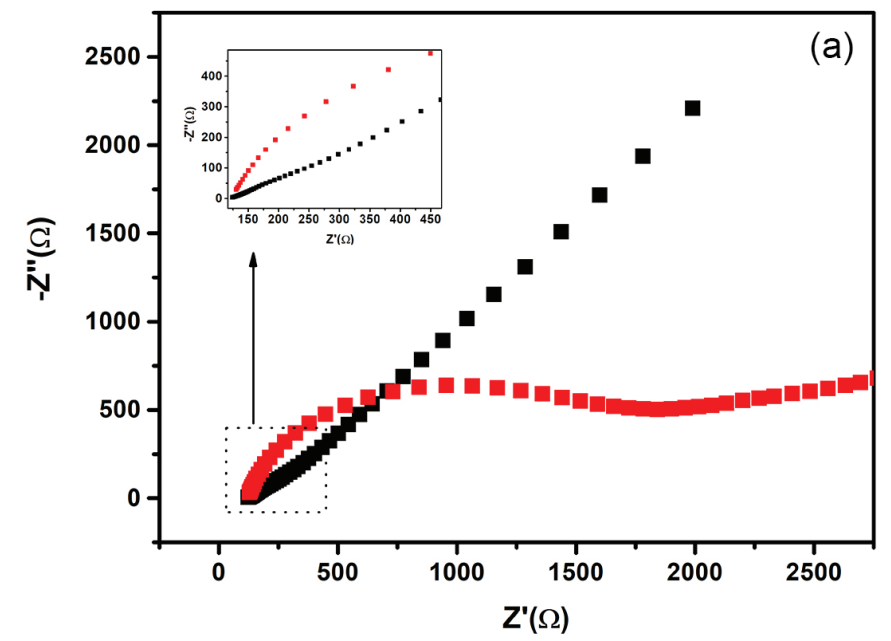

with CRGO provided a $\mathrm{k}_{0}$ value about $22 \%$ higher than the bare surface. This result is in accordance with the EIS analyses, evidencing that the electron transfer is feasible at the CRGO-AuCD surface.

Figure 4 displays the electrochemical behavior of the model phenolic compound DP obtained at AuCD and CRGO-AuCD surfaces. As can be seen in Figure 4 the modified surface with CRGO provided higher peak current $\left(I_{p}\right)$ (about 1.6-fold and 3.3-fold higher for the cathodic $I_{p}$ and anodic $I_{p}$, respectively) and lower peak separation $\left(\Delta \mathrm{E}_{\mathrm{p}}\right)$ (about 9-fold lower) when compared to the bare surface. The lower peak separation observed at the CRGO-AuCD surface corroborates with the results obtained via EIS, in which the higher reversibility is one clue of a faster electron transfer. Table 1 summarizes the values of $\mathrm{I}_{\mathrm{p}}$ (cathodic and anodic), $\mathrm{E}_{\mathrm{p}}$ (cathodic and anodic) and $\Delta \mathrm{E}_{\mathrm{p}}$ for each surface.

Additionally, aiming to understand the mass transport of the model analyte (DP) at each surface (unmodified and modified with CRGO) a study via cyclic voltammetry was conducted, in which the scan rate was varied in the range between 10 and $1000 \mathrm{mV} \mathrm{s}^{-1}$. Both surfaces presented great linearity $\left(R^{2}>0.99\right)$ in the plot of $I_{p}$ versus square root of scan rate, indicating that the electrochemical processes are controlled by diffusion of the DP onto the both surfaces.

Hydrodynamic voltammograms for the two AuCD and CRGO-AuCD surfaces were generated from amperometric recordings obtained at constant potentials in the range between 0.0 and $+0.8 \mathrm{~V}$. It was possible to observe that the oxidation process of DP was anticipated at CRGO-AuCD in approximately $100 \mathrm{mV}$ (oxidation signal for DP from 0.6 and $0.5 \mathrm{~V}$ for AuCD and CRGO-AuCD, respectively) compared to $\mathrm{AuCD}$. These results obtained by

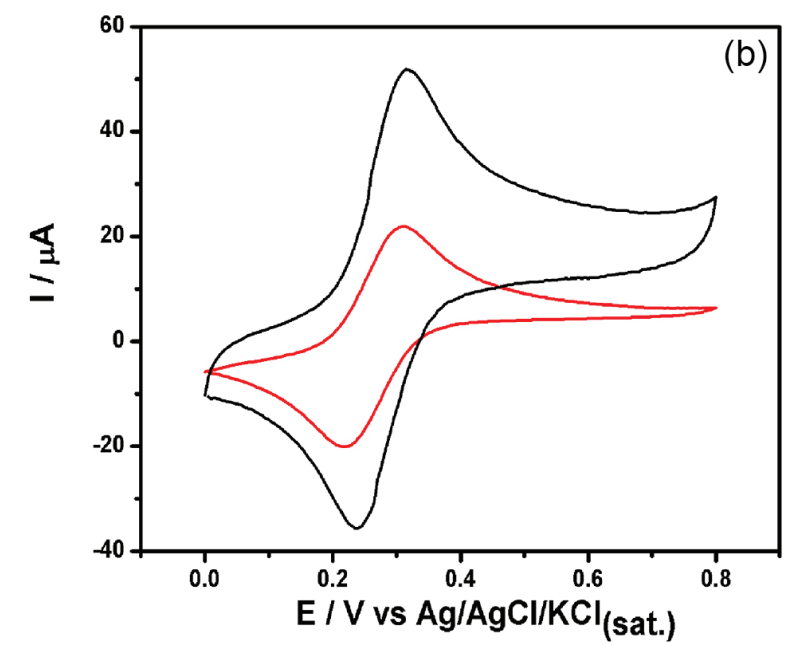

Figure 3. (a) EIS spectra obtained with bare ( $\square$ ) and modified ( $\square$ ) AuCD with CRGO. (b) Cyclic voltammogram recordings of bare (-) and modified (-) electrodes in the presence of $1 / 1 \mathrm{mmol} \mathrm{L}^{-1} \mathrm{~K}_{3} \mathrm{Fe}(\mathrm{CN})_{6} / \mathrm{K}_{4} \mathrm{Fe}(\mathrm{CN})_{6}$ in $0.1 \mathrm{~mol} \mathrm{~L}^{-1} \mathrm{KCl}$ solution. Experimental conditions in (a): frequency range between $0.1 \mathrm{~Hz}$ and $50 \mathrm{kHz}$ with a signal amplitude of $10 \mathrm{mV}$ with 10 data points per frequency decade. Experimental conditions in (b): scan rate: $50 \mathrm{mV} \mathrm{s}{ }^{-1}$; step potential: $5 \mathrm{mV}$. 
Table 1. Values of $\mathrm{I}_{\mathrm{p}}, \mathrm{E}_{\mathrm{p}}$ and $\Delta \mathrm{E}_{\mathrm{p}}$ of DP obtained by cyclic voltammetric data

\begin{tabular}{lccccc}
\hline & $\mathrm{E}_{\mathrm{pc}} / \mathrm{V}$ & $\mathrm{E}_{\mathrm{pa}} / \mathrm{V}$ & $\Delta \mathrm{E}_{\mathrm{p}} / \mathrm{V}$ & $\mathrm{I}_{\mathrm{pa}} / \mu \mathrm{A}$ & $\mathrm{I}_{\mathrm{pc}} / \mu \mathrm{A}$ \\
\hline AuCD & 0.734 & 0.281 & 0.453 & 7.604 & -2.954 \\
CRGO-AuCD & 0.552 & 0.501 & 0.051 & 12.188 & -9.882 \\
\hline
\end{tabular}

AuCD: Au-rewritable compact discs; CRGO-AuCD: chemically reduced graphene oxide Au-rewritable compact discs; $\mathrm{E}_{\mathrm{pc}}$ : cathodic peak potential; $\mathrm{E}_{\mathrm{pa}}$ : anodic peak potential; $\Delta \mathrm{E}_{\mathrm{p}}$ : peak separation; $\mathrm{I}_{\mathrm{pa}}$ : anodic peak current; $\mathrm{I}_{\mathrm{pc}}$ : cathodic peak current.

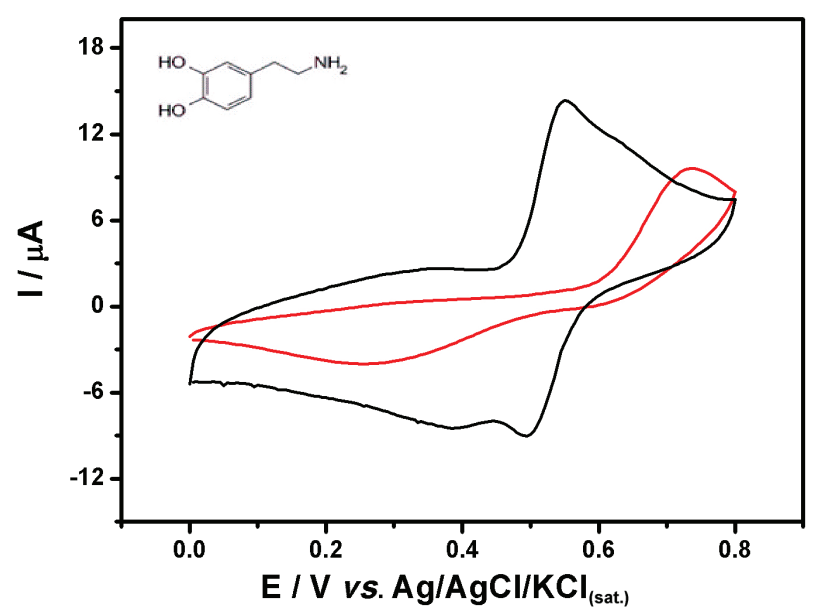

Figure 4. Cyclic voltammetric recordings of bare (-) and modified (-) AuCD with CRGO surfaces in the presence of $1 \mathrm{mmol} \mathrm{L}^{-1} \mathrm{DP}$ in $0.1 \mathrm{~mol} \mathrm{~L}^{-1} \mathrm{HClO}_{4}$ (background electrolyte) at $50 \mathrm{mV} \mathrm{s}^{-1}$ (scan rate) and $5 \mathrm{mV}$ of step potential. Insertion: structural formula of DP.

amperometry for DP are in agreement with the studies of EIS (Figure 3), $\mathrm{R}_{\mathrm{ct}}$ and HET obtained at the CRGO-AuCD surface that indicated a fast electron transfer also favoring kinetically the redox reaction of DP on the CRGO-AuCD surface. It was also possible to observe the increase in the DP current intensity, 55\% higher on CRGO-AuCD compared to AuCD at the potential of $+0.8 \mathrm{~V}$, which was selected for the development of the analytical method for DP in the BIA system with amperometric detection (BIA-AMP). The parameters of BIA-AMP as dispensing rate $\left(16.5-370 \mu \mathrm{L} \mathrm{s}^{-1}\right)$ and volume injection $(25-200 \mu \mathrm{L})$ were optimized. The best conditions based on the highest peak current and repeatability of the electrochemical signal for DP were $370 \mu \mathrm{L} \mathrm{s}^{-1}$ and $100 \mu \mathrm{L}$ for dispensing rate and volume injection, respectively.

From the optimized conditions of the BIA-AMP system, analytical curves (from 1 to $800 \mu \mathrm{mol} \mathrm{L}^{-1}$ ) for DP were obtained at CRGO-AuCD and AuCD electrodes. Figure 5 shows the respective analytical curves.

The slope $\left(0.239 \mu \mathrm{A} \mathrm{L} \mu \mathrm{mol}^{-1}\right)$ of the analytical curve obtained at CRGO-AuCD was about 3 -fold higher than the slope $\left(0.083 \mu \mathrm{A} \mathrm{L} \mathrm{mol}^{-1}\right)$ of the analytical curve obtained at the bare AuCD. The analytical curve for CRGO-AuCD also presented slight improvement in linearity $\left(\mathrm{R}^{2}>0.997\right)$ in comparison to $\mathrm{AuCD}\left(\mathrm{R}^{2}>0.991\right)$.

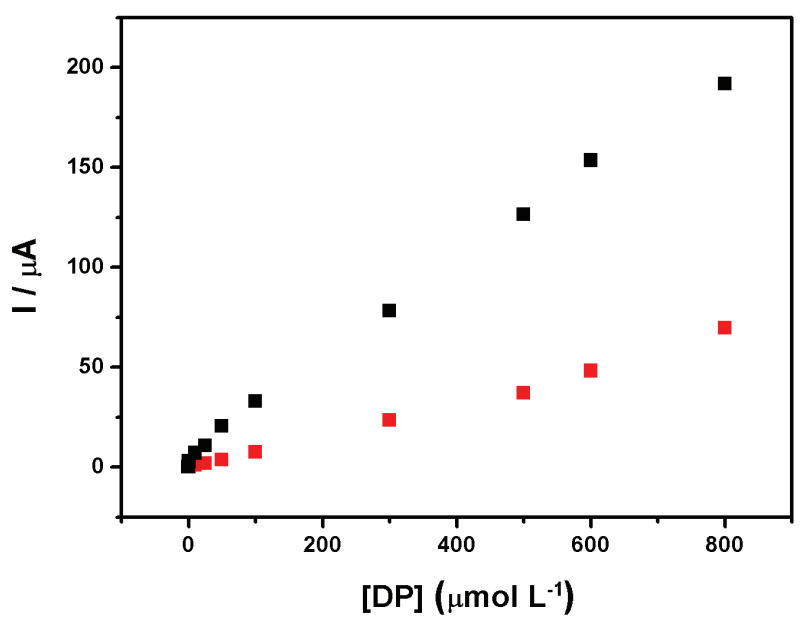

Figure 5. Analytical curves for DP (from 1 to $800 \mu \mathrm{mol} \mathrm{L} \mathrm{L}^{-1}$ ) obtained at bare ( $\square$ ) and modified ( $\square$ ) AuCD with CRGO. Parameters of BIA-AMP: $+0.8 \mathrm{~V}$ (applied potential), $0.1 \mathrm{~mol} \mathrm{~L}^{-1} \mathrm{HClO}_{4}$ (background electrolyte), $100 \mu \mathrm{L}$ (injection volume) and $370 \mu \mathrm{L} \mathrm{s}^{-1}$ (dispensing rate).

In addition, Figure 6 shows the analytical curves (1-800 $\left.\mu \mathrm{mol} \mathrm{L}^{-1}\right)$ of increasing and decreasing concentrations of DP on the CRGO-AuCD electrode. Analytical curves of increasing $\left(0.239 \mu \mathrm{A} \mathrm{L} \mu \mathrm{mol}^{-1}\right)$ and decreasing $\left(0.235 \mu \mathrm{A} \mathrm{L} \mu \mathrm{mol}^{-1}\right)$ analytical curves were similar and the amperogram reveals absence of memory effect (no adsorption of the analyte or its oxidation product on the electrode surface was observed).

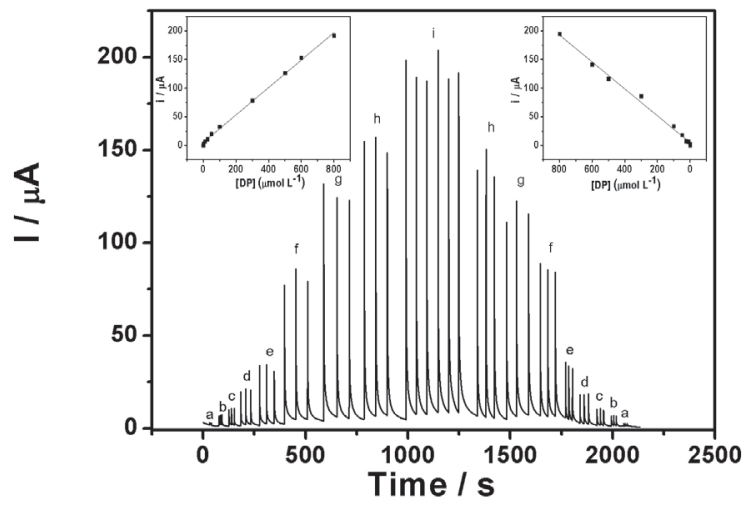

Figure 6. Amperogram obtained from triplicate injections of solutions containing increasing and decreasing concentrations of DP: (a) 1; (b) 10; (c) 25; (d) 50; (e) 100; (f) 300; (g) 500; (h) 600 and (i) $800 \mu \mathrm{mol} \mathrm{L}^{-1}$. Insets are the analytical curves for increasing and decreasing concentrations. Parameters of BIA-AMP: $+0.8 \mathrm{~V}$ (applied potential), $0.1 \mathrm{~mol} \mathrm{~L}^{-1} \mathrm{HClO}_{4}$ (background electrolyte), $100 \mu \mathrm{L}$ (injection volume) and $370 \mu \mathrm{L} \mathrm{s}^{-1}$ (dispensing rate). 
The instrumental precision was evaluated by the relative standard deviation (RSD) of consecutive measurements $(n=10)$ of standard solutions of DP at concentrations of 1 and $10 \mu \mathrm{mol} \mathrm{L}^{-1}$ for CRGO-AuCD and AuCD. The values of RSD for $1 \mu \mathrm{mol} \mathrm{L}^{-1}$ were 4.6 and $4.6 \%$ for CRGO-AuCD and $\mathrm{AuCD}$, respectively. For $10 \mu \mathrm{mol} \mathrm{L} \mathrm{L}^{-1}$, the values were 11.6 and $6.4 \%$, respectively, showing more stable and precise measurements obtained at the AuCD surface after modification with CRGO.

In addition, by using the BIA-AMP system, the repeatability of different $(n=10)$ modifications of the AuCD surface with CRGO by drop casting was monitored through the intensity and profile of the peak current for consecutive injections $(\mathrm{n}=10)$ of $\mathrm{DP}\left(100 \mu \mathrm{mol} \mathrm{L} \mathrm{L}^{-1}\right)$ recorded at 10 different modified electrodes. The average current value obtained on each electrode was used to calculate the current variation. The RSD value was $5.9 \%$. This value indicates high reproducibility of electrode modification procedure by drop casting CRGO on AuCD surfaces.

The limits of detection (LOD) values were calculated from three times the standard deviation for ten random measurements of the blank (current background noise) divided by the slope of the analytical curve. The LOD for CRGO-AuCD (120 $\left.\mathrm{nmol} \mathrm{L}^{-1}\right)$ was about 2-fold lower compared to the AuCD electrode $\left(270 \mathrm{nmol} \mathrm{L}^{-1}\right)$. The best analytical performance for the amperometric detection of DP using the CRGO-AuCD electrode can be explained by the greater stability of the signal at this electrode (lower RSD values) and higher electron transfer.

The analytical frequency (AF) was calculated using the amperometric transient signals from the instrumental precision tests. The AF value obtained at CRGO-AuCD was

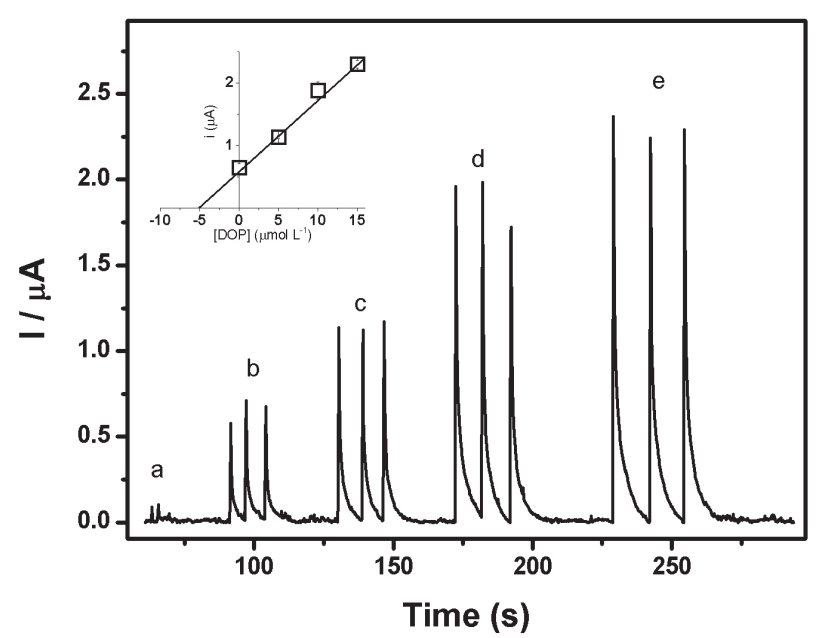

Figure 7. Amperogram and curve of standard addition (inset) for DP (5-15 $\left.\mu \mathrm{mol} \mathrm{L}^{-1}\right)$ in a fortified synthetic saliva sample. (a) Artificial saliva sample without fortification; (b) fortified saliva sample with $5.0 \mu \mathrm{mol} \mathrm{L}^{-1}$ DP; increasing concentrations of DP: (c) 5, (d) 10 and (e) $15 \mu \mathrm{mol} \mathrm{L} \mathrm{L}^{-1}$. Parameters of BIA-AMP: $+0.8 \mathrm{~V}$ (applied potential), $0.1 \mathrm{~mol} \mathrm{~L}^{-1} \mathrm{HClO}_{4}$ (background electrolyte), $100 \mu \mathrm{L}$ (injection volume) and $370 \mu \mathrm{L} \mathrm{s}^{-1}$ (dispensing rate).

estimated as $370 \mathrm{~h}^{-1}$ that is higher than the value obtained on bare $\operatorname{AuCD}\left(270 \mathrm{~h}^{-1}\right)$. These results also indicate a faster electron transfer provided by CRGO, in agreement with previous data presented in the text.

As proof-of-concept, the accuracy of the analytical method developed with the CRGO-AuCD electrode was evaluated by means of a recovery test (Figure 7) for DP $\left(5 \mu \mathrm{mol} \mathrm{L}{ }^{-1}\right)$ in a synthetic saliva sample. An acceptable recovery value of $98.6 \pm 0.9 \%$ was obtained.

Table 2 presents a brief comparison between the analytical performance for the CRGO-AuCD sensor and other sensors modified with different graphene or graphene oxide (RGO)

Table 2. Comparison of different graphene-based electrochemical sensors developed for DP determination

\begin{tabular}{|c|c|c|c|c|}
\hline Electrode & Electrochemical technique & Linear range / $(\mu \mathrm{mol} \mathrm{L}-1)$ & $\mathrm{LOD} /\left(\mu \mathrm{mol} \mathrm{L}^{-1}\right)$ & Reference \\
\hline Drop-casting-GO/GCE & $\mathrm{CV}$ & $4-100$ & 2.46 & 39 \\
\hline $\mathrm{Co}_{3} \mathrm{O}_{4} / \mathrm{RGO} / \mathrm{CTAB} / \mathrm{CPE}$ & DPV & $70-160$ & 2.46 & 40 \\
\hline RGO/AuNPs/ITO & amperometry & $0.1-30$ & 1.28 & 41 \\
\hline AuNPs/RGO/GCE & DPV & $7-41$ & 1.40 & 42 \\
\hline RGO-PAMAM-MWCNT-AuNPs/GCE & DPV & $10-320$ & 3.30 & 43 \\
\hline ERGO/GCE & DPV & $0.5-60$ & 0.50 & 44 \\
\hline RGO/AuNPs/ITO & DPV & $1-100$ & 0.60 & 45 \\
\hline IL-graphene/GCE & DPV & $1-100$ & 0.33 & 46 \\
\hline $\mathrm{ErGO} / \mathrm{CFE}$ & DPV & $1.5-225$ & 0.77 & 47 \\
\hline GO-BAMB-Co(OH $)_{2} / \mathrm{GCE}$ & DPV & $3-100$ & 0.40 & 48 \\
\hline $\mathrm{GO} / \mathrm{GCE}$ & DPV & $5-200$ & 2.00 & 49 \\
\hline Graphene nanosheet & DPV & $4-52$ & 0.60 & 50 \\
\hline CRGO-AuCD & amperometry & $1-800$ & 0.12 & this work \\
\hline
\end{tabular}

LOD: limit of detection; GO: graphene oxide; GCE: glassy carbon electrode; $\mathrm{Co}_{3} \mathrm{O}_{4}$ : cobalt(III) oxides; RGO: reduced graphene oxide; CTAB: cetyl trimethylammonium bromide; CPE: carbon paste electrode; AuNPs: gold nanoparticles; ITO: indium tin oxide electrode; PAMAM: poly(amino-amine); MWCNTs: multi-walled carbon nanotubes; ERGO: electrochemically reduced graphene oxide; CFE: carbon fiber electrode; $\mathrm{Co}(\mathrm{OH})_{2}: \mathrm{cobalt}$ hydroxide; BAMB: 1,4-bis(aminomethyl)benzene; CV: cyclic voltammetry; DPV: differential pulse voltammetry. 
materials with gold nanoparticles (AuNPs) described in the literature for the determination of DP. It was possible to notice that the coupling of this sensor with amperometric detection using the BIA system provided a broader linear range and lower LOD value in comparison to these works. The best analytical performance can be explained due to the homogeneous surface modification of AuCD with CRGO by using the proposed modification procedure, as shown in SEM (Figure 1) and AFM (Figure 3) images.

\section{Conclusions}

We have demonstrated the drop-casting modification with CRGO of a low-cost gold sensor produced from AuCD. SEM and AFM images demonstrated homogeneous distribution of the modified surface, and larger surface area and roughness of the modified sensor. Electron transfer to redox probes is faster on the modified CRGO-AuCD surface evidenced by EIS, $\mathrm{R}_{\mathrm{ct}}$ and HET $\left(\mathrm{k}_{0}\right)$ values which highlights the higher electrocatalytic activity provided CRGO. The higher current intensity for DP observed in the modified CRGO sensor for cyclic voltammetry and amperometry is due to the increase of the surface area of the modified AuCD and electroactive area, which corroborates with the greater amount of surface material observed in the images of CRGO-AuCD (SEM) and with the highest roughness verified (AFM). The CRGO-AuCD sensor proved to be adequate and stable when coupled to a BIA system for continuous amperometric detection. The developed analytical method for DP using CRGO-AuCD obtained a wide linear range (larger than some works described in the literature), besides being sensitive and precise. In addition, the analysis of synthetic saliva sample presented a satisfactory result, with recovery of $98.6 \%$, indicating a potential use of the CRGO-AuCD sensor for the analysis of biological samples.

\section{Acknowledgments}

The authors are grateful to FAPEMIG (PPM00640-16), CNPq (307271/2017-0), CAPES (001 and 23038.007073/2014-12) and INCTBio - CNPq (465389/2014-7).

\section{References}

1. Heyrovský, M.; Chem. Rec. 2012, 12, 14.

2. Wang, J.; Analytical Electrochemistry, $2^{\text {nd }}$ ed.; Wiley: New York, 2006.

3. Oliveira, R. S.; Practical Electroanalysis: Overcoming Drawbacks and Going Further; Saito, Y.; Kikuchi, T., eds.; Nova Science Publishers: New York, United States, 2014, ch. 6.
4. Labib, M.; Sargent, E. H.; Kelley, S. O.; Chem. Rev. 2016, 16, 116.

5. Bertotti, M.; Lowinsoh, D.; Quim. Nova 2006, 29, 1318.

6. Edris, N. M. M. A.; Abdullah, J.; Kamaruzaman, S.; Saiman, M. I.; Sulaiman, Y.; Arab. J. Chem. 2018, 11, 1301.

7. Souza, M. F. B.; Quim. Nova 1997, 2, 20.

8. Mello, G. C.; Graphite: Sailing in a Cost-Effective Electron Sea; Campbell, Q. C., ed.; Nova Science Publishers: New York, United States, 2013, ch. 5.

9. Ansari, M. Z.; Johari, R.; Siddiqi, W. A.; Mater. Res. Express. 2019, 6, 055027

10. Tajik, S.; Beitollahi, H. A.; Anal. Bioanal. Chem. 2019, 6, 171.

11. Gao, F.; Cai, X.; Wang, X.; Gao, C.; Liu, S.; Gao, F.; Wang, Q.; Sens. Actuators, B 2013, 186, 380.

12. Geim, A. K.; Novoselov, K. S.; Nat. Mater. 2007, 6, 183.

13. Park, S.; Ruoff, R. S.; Nat. Nanotechnol. 2009, 4, 217.

14. Rocha, D. P.; Dornellas, R. M.; Cardoso, R. M.; Narciso, L. C. D.; Silva, M. N. T.; Nossol, E.; Richter, E. M.; Munoz, R. A. A.; Sens. Actuators, B 2018, 254, 701.

15. Chen, Y.; Liua, L.; Wang, M.; Wang, C.; Hu, X.; Wang, G.; Sens. Actuators, B 2013, 177, 555.

16. Cardoso, R. M.; Montes, R. H. O.; Lima, A. P.; Dornellas, R. M.; Nossol, E.; Richter, E. M.; Munoz, R. A. A.; Electrochim. Acta 2015, 176, 36.

17. Tan, C. W.; Tan, K. H.; Ong, Y. T.; Mohamed, S. H. S. A. R.; Tan, Z. S. H.; Environ. Chem. Lett. 2012, 10, 265.

18. Mittal, M.; Kumar, A. C.; Sens. Actuators, B 2014, 203, 349.

19. Zaporotskova, I. V.; Boroznina, N. P.; Parkhomenko, Y. N.; Kozhitov, L. V.; Mod. Electron. Mater. 2016, $2,95$.

20. Faria, L. V.; Pereira, J. F. S.; Azevedo, G. C.; Matos, M. A. C.; Munoz, R. A. A.; Matos, R. C.; J. Braz. Chem. Soc. 2019, 30, 1947.

21. Rocha, D. P.; Silva, M. N. T.; Cardoso, R. M.; Castro, S. V. F.; Tormin, T. F.; Richter, E. M.; Nossol, E.; Munoz, R. A. A.; Sens. Actuators, B 2018, 269, 293.

22. Lima, A. P.; Souza, R. C.; Silva, M. N. T.; Gonçalves, R. F.; Nossol, E.; Richter, E. M.; Lima, R. C.; Munoz, R. A. A.; Sens. Actuators, B 2018, 262, 646.

23. Lin, Q.; Batchelor-McAuley, C.; Compton, R. C.; J. Phys. Chem. C 2015, 119, 1489.

24. Angnes, L.; Richter, E. M. Augelli, M. A.; Kume, G. H.; Anal. Chem. 2000, 72, 5503.

25. Honeychurch, K. C.; Trends Anal. Chem. 2017, 93, 51.

26. Felix, F. S.; Daniel, D.; Matos, J. R.; Lago, C. L.; Angnes, L.; Anal. Chim. Acta 2016, 928, 32.

27. Stuart, E. J. E.; Tschulik, K.; Lowinsohn, D.; Cullen, J. T.; Compton, R. G.; Sens. Actuators, B 2014, 195, 223.

28. Munoz, R. A. A.; Matos, R. C.; Angnes, L.; Talanta 2001, 55, 855. 
29. Rocha, D. P.; Cardoso, R. M.; Tormin, T. F.; Araujo, W. R.; Munoz, R. A. A.; Richter, E. M.; Angnes, L.; Electroanalysis 2018, 30, 1386.

30. Perry, M.; Li, Q.; Kennedy, R. T. K.; Anal Chim. Acta 2009, $653,1$.

31. Schwab, K. O.; Heubel, G.; Bartels, H.; Eur. J. Clin. Chem. Clin. Biochem. 1992, 30, 541.

32. Kennedy, B.; Dillon, E.; Mills, P. J.; Ziegler, M. G.; Life Sci. 2001, 69, 87.

33. Takai, N.; Yamaguchi, M.; Aragaki, T.; Eto, K.; Uchihashi, K.; Nishikawa, Y.; Arch. Oral Biol. 2004, 49, 963.

34. Sanna, G.; Pilo, M. I; Piu, P. C.; Spano, N.; Tapparo, A.; Campus, G. G.; Seeber, R.; Talanta 2002, 58, 979.

35. Pedrotti, J. J.; Angnes, L.; Gutz, I. G. R.; Electroanalysis 1996, $8,673$.

36. Cardoso, R. M.; Mendonça, D. M. H.; Silva, W. P.; Silva, M. N. T.; Nossol, E.; Silva, R. A. B.; Richter, E. M.; Munoz, R. A. A.; Anal. Chim. Acta 2018, 1033, 49.

37. Cardoso, R. M.; Dornellas, R. M.; Lima, A. P.; Montes, R. H. O.; Richter, E. M.; Munoz, R. A. A.; J. Braz. Chem. Soc. 2017, 28, 1650 .

38. Thakur, B.; Bernalte, E.; Smith, J. P.; Linton, P. E.; Sawant, S. N.; Banks, C. E.; Foster, C. W.; C 2016, 2, 14.

39. Kim, Y. R.; Bong, S.; Kang, Y. J.; Yang, Y.; Mahajan, R. K.; Kim, J. S.; Kim, H.; Biosens. Bioelectron. 2010, 25, 2366.
40. Venu, M.; Gupta, V. K.; Agarwa, S.; Venkateswarlu, S.; Madhavil, G.; Int. J. Electrochem. Sci. 2010, 13, 11702.

41. Choo, S. S.; Kang, E. S.; Song, I.; Lee, D.; Choi, J. W.; Kim, T. H.; Sensors 2017, 17, 861.

42. Wang, C.; Du, J.; Wang, H.; Zou, C.; Jiang, F.; Yang, P.; Du, Y.; Sens. Actuators, B 2014, 204, 302.

43. Wang, S.; Zhang, W.; Zhong, X.; Chai, Y.; Yuan, R.; Anal. Methods 2015, 7, 1471.

44. Yang, L.; Liu, D.; Huang, J.; Tianyan You, T.; Sens. Actuators, B 2014, 193, 166.

45. Jiang, C.; Zeng, X.; Wu, B.; Zeng, Q.; Pang, W.; Tang, J.; Sci. China: Chem. 2017, 60, 151.

46. Liu, P.; Dong, M.; Lu, J.; Guo, H.; Lu, X.; Liu, X.; Ionics 2015 , 21, 1111 .

47. Yang, B.; Wang, B.; Du, J.; Fu, Y.; Yang, P.; Du, Y.; Colloids Surf., A 2014, 456, 146.

48. Ejaz, A.; Joo, Y.; Jeon, S.; Sens. Actuators, B 2017, 240, 297.

49. Wang, Y.; Li, Y.; Tang, L.; Lu, J.; Li, J.; Electrochem. Commun. 2009, 11, 889 .

50. Liu, S. Q.; Sun, W. H.; Hu, F. T.; Sens. Actuators, B 2012, 173 , 497.

Submitted: April 17, 2019

Published online: August 21, 2019 